2018-10

\title{
Can transplanting enhance mobile marine invertebrates in ecologically engineered rock pools?
}

\author{
Morris, $\mathrm{RL}$
}

http://hdl.handle.net/10026.1/12671

\subsection{6/j.marenvres.2018.08.008 \\ Marine Environmental Research \\ Elsevier}

All content in PEARL is protected by copyright law. Author manuscripts are made available in accordance with publisher policies. Please cite only the published version using the details provided on the item record or document. In the absence of an open licence (e.g. Creative Commons), permissions for further reuse of content should be sought from the publisher or author. 
Pre-proof: Please see Morris, R.L., Martinez, A.S., Firth, L.B. and Coleman, R.A., 2018. Can transplanting enhance mobile marine invertebrates in ecologically engineered rock pools?. Marine Environmental Research 141: 119-127. https://www.sciencedirect.com/science/article/pii/S0141113618303404

1 Can transplanting enhance mobile marine invertebrates in ecologically engineered rock

2 pools?

3 Rebecca L. Morris ${ }^{1}$, Aline S. Martinez ${ }^{1}$, Louise B. Firth ${ }^{2}$ and Ross A. Coleman ${ }^{1}$

4

$5 \quad{ }^{1}$ Centre for Research on Ecological Impacts of Coastal Cities, School of Life and

6 Environmental Sciences, The University of Sydney, NSW 2006, Australia, ${ }^{2}$ School of

7 Biological and Marine Sciences, University of Plymouth, Drake Circus PL4 8AA, UK.

8

9 Corresponding Author:

10 Rebecca Morris, Current address: National Centre for Coasts and Climate, School of

11 BioSciences, The University of Melbourne, VIC 3010, Australia.

12 Email rebecca.morris@unimelb.edu.au, Tel. +61 423392882

Running headline: Artificial rock pool colonisation 
Pre-proof: Please see Morris, R.L., Martinez, A.S., Firth, L.B. and Coleman, R.A., 2018. Can transplanting enhance mobile marine invertebrates in ecologically engineered rock pools?. Marine Environmental Research 141: 119-127. https://www.sciencedirect.com/science/article/pii/S0141113618303404

\section{Abstract}

25

The field of eco-engineering has burgeoned in recent years in response to the proliferation of artificial structures. Adding water-retaining features to seawalls has been successful in increasing biodiversity relative to the surrounding structure. Artificial rock pools may not, however, completely mimic natural rock pools. Here, we compared natural colonisation, through dispersal and recruitment, of intertidal mobile species to water-retaining flowerpots on seawalls with that into rock pools. This represents the more usual 'passive' approach to eco-engineering where features are built to enhance biodiversity and are allowed to colonise naturally, as opposed to seeding or transplanting organisms to features. While flowerpots supported some mobile species not found on the seawall, other species common on natural shores did not recruit to flowerpots. Thus, in a second experiment we tested the effectiveness of an 'active' approach through transplanting mobile organisms to flowerpots to expedite the colonisation process. For the species examined, however, most individuals did not stay in the flowerpots for more than 24 hours after being transplanted. Further understanding of the processes (e.g. dispersal distances, recruitment) influencing colonisation of eco-engineered habitats is needed to effectively inform management of marine infrastructure, particularly for projects targeted at restoration rather than enhancement.

Key words: Benthic ecology; Biodiversity; Coastal structures; Ecosystem management; Green engineering; Seeding; Sydney; Urbanisation 
Pre-proof: Please see Morris, R.L., Martinez, A.S., Firth, L.B. and Coleman, R.A., 2018. Can transplanting enhance mobile marine invertebrates in ecologically engineered rock pools?. Marine Environmental Research 141: 119-127. https://www.sciencedirect.com/science/article/pii/S0141113618303404

47

\section{Introduction}

Artificial structures are proliferating in the coastal environment (Dugan et al., 2011; Firth et al., 2016a). In some areas, more than $50 \%$ of the natural foreshore has been replaced by artificial structures, such as seawalls, breakwaters and pilings (Dugan et al., 2011; Chee et al., 2017). In addition to loss and fragmentation of natural habitats (Goodsell et al., 2007; Heery et al., 2017), artificial structures provide novel habitats for colonisation, which often support fewer (Chapman, 2003; Gittman et al., 2015) and different combinations of species (Connell and Glasby, 1999; Davis et al., 2002; Bulleri and Chapman, 2004; Bulleri et al., 2005; Lam et al., 2009) in comparison to those on natural hard substrata. In response to the impacts of artificial structures on marine communities (Bulleri and Chapman, 2010; Bishop et al., 2017), an increasing research effort has focused on ecological engineering of artificial structures to facilitate greater colonisation of native species (see reviews: Chapman and Underwood, 2011; Dafforn et al., 2015a; Firth et al., 2016a). A fundamental difference between artificial structures and natural shores is the lack of physical complexity and microhabitat diversity (e.g. rock pools, crevices, pits) on artificial structures for organisms to colonise (Chapman, 2003). To combat the homogeneous habitat provided by much built infrastructure, adding complex surfaces and novel habitats either retrospectively or during construction has been successful at increasing biodiversity relative to that which is found living on the surrounding structure (Chapman and Underwood, 2011; Firth et al., 2014a).

In intertidal systems, mobile organisms are notably absent from artificial structures (Chapman, 2003). The majority of work in the intertidal zone has been done on groynes and seawalls (Strain et al., 2018), hence that is where most of our current knowledge comes from. 
Pre-proof: Please see Morris, R.L., Martinez, A.S., Firth, L.B. and Coleman, R.A., 2018. Can transplanting enhance mobile marine invertebrates in ecologically engineered rock pools?. Marine Environmental Research 141: 119-127. https://www.sciencedirect.com/science/article/pii/S0141113618303404

70

Although certain mobile species have been recorded in greater abundances on seawalls compared to rocky shores (e.g. some limpets and chitons; Bulleri et al., 2005), for the majority of mobile species, abundances tend to be lower than on natural rocky shores (Bulleri and Chapman, 2004; Bulleri et al., 2005). Further, a subset of mobile species that are found on rocky shores are not found on seawalls (Chapman, 2003), and similar patterns have been observed for other structures (e.g. groynes and breakwaters, Firth et al., 2013; Aguilera et al., 2014). Species that are unable to live on artificial structures are often those found in microhabitats that tend to be absent on walls, such as rock pools and deep crevices (Chapman, 2003; Firth et al., 2013). Seawalls can vary in geology and topography (Chapman, 2003), and walls that are characterised by more crevices can support greater numbers of particular mobile species (Moreira et al., 2007). Similarly, some gastropods (e.g. Morula marginalba) only inhabited seawalls when other habitat-forming organisms were present (e.g. oysters) (Jackson et al., 2008). Thus, the introduction of eco-engineered microhabitats (e.g. rock-pools, crevices, pits) might enable the range of certain species to extend onto seawalls that would otherwise not be found there and therefore enhance native biodiversity on seawalls.

A 'passive' approach has been taken for a majority of eco-engineering projects to date. This is the "build it and they will come" scenario (Palmer et al., 2008), where ecoengineered features are installed and an emergent assemblage as a product of recruitment and/or dispersal and succession is measured (hereafter 'colonisation') after a period of time. Colonisation of mobile species that are not found on nearby existing artificial structures to eco-engineered habitats will depend on recruitment from the water column (Chapman and Underwood, 2011). In contrast, Any mobile species found on the existing artificial structure 
Pre-proof: Please see Morris, R.L., Martinez, A.S., Firth, L.B. and Coleman, R.A., 2018. Can transplanting enhance mobile marine invertebrates in ecologically engineered rock pools?. Marine Environmental Research 141: 119-127. https://www.sciencedirect.com/science/article/pii/S0141113618303404

would be able to disperse into eco-engineered habitats by moving from the surrounding structure (Underwood, 1977). Thus, the assemblage that colonises eco-engineered habitats will depend on both the pre-existing surrounding benthic assemblage as a source for dispersal and the larval pool as a source for recruitment.

Differential recruitment is one of the simplest models that could explain any differences between assemblages found on natural shores and those in eco-engineered habitats. Indeed, differential recruitment of organisms has been shown to help explain the difference in intertidal assemblages found on seawalls and rocky shores (Bulleri, 2005), as well as between shaded and non-shaded habitat on seawalls (Blockley and Chapman, 2006), on seawalls which are sheltered or exposed to wave action (Blockley and Chapman, 2008) and on seawalls of different materials (Iveša et al., 2010). There is considerable research over many decades showing that small-scale habitat features, such as free space (Bracewell et al., 2013), surface texture and chemistry (Coombes et al., 2015; McManus et al., in press), holes, cracks and crevices (Kohler et al., 1999), patterns of water flow (Mullineaux and Butman, 1991) and interactions between various factors (Knights et al., 2012) influence recruitment of intertidal species. Recruitment plates or pads are often used experimentally to provide a new and standardised substratum to test for differences in recruitment among particular treatments (e.g. McGrath et al., 1994; Blockley and Chapman, 2006). Many intertidal mobile species, however, naturally recruit to softer biogenic substratum, such as algal turfs (Chapman et al., 2005; Matias, 2013). For these species, artificial units of habitat (AUHs) made of synthetic turf have been used as algal mimics to study colonisation to different habitats (Kelaher, 2005; Matias, 2013). Artificial units are recruited to quickly by a large diversity and number of 
Pre-proof: Please see Morris, R.L., Martinez, A.S., Firth, L.B. and Coleman, R.A., 2018. Can transplanting enhance mobile marine invertebrates in ecologically engineered rock pools?. Marine Environmental Research 141: 119-127. https://www.sciencedirect.com/science/article/pii/S0141113618303404

intertidal mobile invertebrates, including juveniles of those found as adults in rock pools and on open rock (Matias, 2013).

With respect to eco-engineering of artificial shorelines, the focus has been on comparing assemblages among natural and/or surrounding substrata at various stages of succession (e.g. Browne and Chapman, 2014; Firth et al., 2014b; Evans et al., 2015), but few studies have focused specifically on early life history stages (but see Coombes et al., 2015). An understanding of how eco-engineered habitats are colonised can be useful to management if a specific species or assemblage is targeted, for example the chance of colonisation of these species may be enhanced by deploying novel habitats at their peak time of recruitment (Chapman and Underwood, 2011). An alternative method of manipulating the assemblage that develops on artificial structures (e.g. seawalls, breakwaters) or eco-engineered habitats (i.e. the added habitat) is to take a more 'active' approach by 'seeding' the structures with cultured species (eg. oysters-or kelp, Strain et al., 2017; Walls et al., In review.), or through transplanting individuals from natural populations (eg. algae, Perkol-Finkel et al., 2012). An active approach may be taken by a way of 'nudging nature' to target desirable species or expedite the colonisation process and does not depend on the vagaries of natural recruitment. Such active management as a tool has not been tested for mobile invertebrates.

Here, water-retaining 'flowerpots' (Browne and Chapman, 2014; Morris et al., 2017) were attached to vertical seawalls in Sydney Harbour, Australia, with the objective to provide habitat for at least some of the mobile species that were lacking on seawalls (Chapman, 2003). Indeed, both previous (Chapman and Blockley, 2011; Browne and Chapman, 2011, 2014) and subsequent (Morris et al. in press) studies showed that the addition of water retaining features (cavities and flowerpots) onto seawalls in Sydney Harbour extended the 
Pre-proof: Please see Morris, R.L., Martinez, A.S., Firth, L.B. and Coleman, R.A., 2018. Can transplanting enhance mobile marine invertebrates in ecologically engineered rock pools?. Marine Environmental Research 141: 119-127. https://www.sciencedirect.com/science/article/pii/S0141113618303404

habitat for some species that were otherwise rare, or not found on that seawall. However, other species that were common on natural shores in the harbour, were not present on the seawall and did not recruit to artificial rock pools. On natural shores, some of these species are confined to pools at low tide (e.g. starfish). Some gastropods, however, may show preference for rock pools (e.g. Austrocochlea porcata, Underwood, 1976) but can be found on emergent rock, and some use rock pools as refugia under harsh conditions (Underwood, 1977).

In two sequential experiments, we tested passive and active approaches to facilitate the colonisation of mobile invertebrates into flowerpots. For the passive approach, we compared the emergent assemblage (as a product of recruitment and dispersal from the surrounding habitat) of mobile species between natural rock pools and flowerpots. Further, we measured recruitment to rock pools and flowerpots using AUHs to determine whether differences in mobile species was due to a lack of recruitment into flowerpots, or the dispersal of species into rock pools from surrounding emergent substrata. Where species did not recruit into flowerpots, an 'active' experiment tested whether it was possible to introduce individuals by transplanting target species into flowerpots. Specifically, we predicted: (1) the assemblage (i.e. composition and abundance) of mobile species will differ between flowerpots and natural rock pools; (2) any differences in mobile species between natural rock pools and flowerpots was because the mobile species not found in pots only recruit to natural rock pools; (3) alternatively, species only found on natural shores can disperse between natural pools and the surrounding rock, but cannot disperse into flowerpots, as these species are not found on seawalls and; (4) when these species are transplanted into flowerpots, the 
Pre-proof: Please see Morris, R.L., Martinez, A.S., Firth, L.B. and Coleman, R.A., 2018. Can transplanting enhance mobile marine invertebrates in ecologically engineered rock pools?. Marine Environmental Research 141: 119-127. https://www.sciencedirect.com/science/article/pii/S0141113618303404

proportion that remains in flowerpots will be equal to those translocated into natural rock pools becattse flowerpots do serve as stitable habitat for these species.

\section{Methods}

\subsection{Experiment 1: Passive approach}

Concrete flowerpots $(7 \mathrm{~L}, 315 \mathrm{~mm}$ diameter, modified from those developed by Browne and Chapman (2011)) were attached to seawalls at the mid-shore tidal level at Blackwattle Bay $\left(33.8720^{\circ} \mathrm{S} 151.1991^{\circ}\right.$ E, Figure 2), Sydney Harbour (Morris et al., 2017; Figure 1b). Twenty flowerpots were deployed onto concrete and sandstone seawalls in December 2013 (10 flowerpots) and February 2014 (10 flowerpots) at four sites (5 at each site, $\sim 4 \mathrm{~m}$ apart) that were separated by at least $100 \mathrm{~m}$. Natural rock pools were sampled at Mrs Macquarie's Point $\left(33.8597^{\circ} \mathrm{S} 151.2225^{\circ} \mathrm{E}\right)$, which was the closest natural rocky shore (Figure 2). The rocky shore at Mrs Macquarie's Point was divided into two sites (40 and 50 $\mathrm{m}$ long), separated by at least $100 \mathrm{~m}$. Natural rock pools had established communities and were therefore cleared of all biota at the start of the experiment to make the substrata comparable to new flowerpots with respect to any existing biota. To clear the pools, sponges were used to drain the water and sessile invertebrates were removed using a metal paint scraper and algae were removed with a metal brush. The pools were then washed with dilute hydrochloric acid (Bondall, $320 \mathrm{~g} / \mathrm{L}$ ) to remove any remaining biofilms (Underwood and Skilleter, 1996). 
Pre-proof: Please see Morris, R.L., Martinez, A.S., Firth, L.B. and Coleman, R.A., 2018. Can transplanting enhance mobile marine invertebrates in ecologically engineered rock pools?. Marine Environmental Research 141: 119-127. https://www.sciencedirect.com/science/article/pii/S0141113618303404

181

\subsubsection{Colonisation of flowerpots and natural rock pools through dispersal and recruitment}

Natural rock pools and flowerpots (the same over time, $n=3$ ) were sampled fortnightly for the first four months following installation of the flowerpots in December 2013, monthly thereafter until 1 year and quarterly until 18 months. The results presented here are part of a larger dataset comparing different types of artificial rock pools, which determined the replicate number (Morris, 2016). Mobile animals were counted for the whole available substratum and abundance standardised to number per unit area (density). To account for potential non-independence over time, analyses were done for the last time point only, however, presence/absence of all species over the entire 18 months has been presented in Table 1. A multivariate difference in the assemblage between rock pools and flowerpots was determined using permutational multivariate analyses of variance (PERMANOVA, Anderson 2001) from 9999 permutations of the data. If there were not enough permutations to get a reasonable test (less than 100), the Monte-Carlo P value was used (Anderson et al. 2008). A SIMPER analysis (Clarke 1993) was used to identify the taxa contributing most to significant differences between habitats. A threshold of $\geq 10 \%$ contribution was chosen to select the most 'important' taxa (Bulleri 2005).

\subsubsection{Patterns of recruitment to AUHs between flowerpots and natural rock pools}

In February 2014, rock pools ( $\mathrm{n}=5)$ were cleared at Mrs Macquarie's Point at the same time as the flowerpots were installed, as described above. In each replicate rock pool or flowerpot, one AUH was deployed to measure recruitment $\left(10 \times 10 \mathrm{~cm}^{2}\right.$, polyethylene, 10 mm frond length, 66.2 fronds per $\mathrm{cm}^{2}$; Grass Manufacturers Pty Ltd, Sydney, NSW, 
Pre-proof: Please see Morris, R.L., Martinez, A.S., Firth, L.B. and Coleman, R.A., 2018. Can transplanting enhance mobile marine invertebrates in ecologically engineered rock pools?. Marine Environmental Research 141: 119-127. https://www.sciencedirect.com/science/article/pii/S0141113618303404

Australia). AUHs were deployed vertically into pools and pots (Figure $1 \mathrm{c}, \mathrm{d}$ ). They were attached using cable ties to saddle brackets in rock pools, which were attached to the substratum with screws before the start of the experiment. Drilling may have damaged flowerpots, so instead a steel rod was placed across the diameter of the pot to which the cable ties were attached. Attachment methods meant that there was a gap between the substratum and AUHs in both treatments. This was kept as consistent as possible as the deployment method of AUHs can have an effect on the colonising assemblage (Chapman et al., 2008). The use of turfs to measure recruitment avoided the confounding factor of the existing assemblage on recruitment, as the AUHs could be removed and replaced with new ones, which created a "bare" surface for recruits.

Retrieval and replacement of AUHs was done every two months for a year. Although we did not have a hypothesis about temporal patterns, rRecruitment was measured for one year to maximise sampling all species that recruited at different times over the year (Underwood and Fairweather, 1989). To retrieve the AUHs a plastic bag was placed over each AUH, which prevented individuals escaping and the cable ties were cut to release the turf from the brackets. The entire unit was preserved in $7 \%$ formalin-seawater before being rinsed with freshwater over a $200 \mu \mathrm{m}$ sieve. The animals were then sorted under a dissecting microscope. All decapods, echinoderms and molluscs were identified to the greatest possible taxonomic resolution (e.g. Chapman et al., 2008). Decapods, echinoderms and molluscs were the focus for this study as these were the three main groups forming the emergent mobile assemblage of rock pools and flowerpots (Table 1). Data were summed for each species over the year and the hypothesis that the total number of recruits of certain species differed between habitats was tested using using $\chi^{2}$ tests. These tested any significant difference from 
Pre-proof: Please see Morris, R.L., Martinez, A.S., Firth, L.B. and Coleman, R.A., 2018. Can transplanting enhance mobile marine invertebrates in ecologically engineered rock pools?. Marine Environmental Research 141: 119-127. https://www.sciencedirect.com/science/article/pii/S0141113618303404

the expected frequencies of equal counts of individuals in each habitat. Where the expected value was less than 5 in the $\chi^{2}$ calculations, an exact binomial test was used, which is robust to a small number of observations (Sokal and Rohlf, 2012).

\subsection{Experiment 2: Active approach}

A transplant experiment of those mobile species that were found in rock pools but not (or rarely) flowerpots, from pools to flowerpots, was done to investigate whether seeded individuals could persist in these artificial habitats. At Blackwattle Bay, a further installation of flowerpots in January 2016 was used for this experiment $(n=6)$. The flowerpots were left for a few weeks prior to the start of the experiment, which allowed a biofilm to form (MacLulich 1986, Murphy \& Underwood 2006). An additional natural rocky shore at Fairlight $\left(33.7960^{\circ} \mathrm{S} 151.2770^{\circ} \mathrm{E}\right)$ was used in this experiment (Figure 2). At each location, 2 sites (15 m) were chosen, 30 m apart. Four treatments (Chapman, 1986) were randomly allocated to six rock pools each (or flowerpots; 3 per site): control (untouched animals at Fairlight); disturbance control (animals picked up and placed back in the same rock pool at Fairlight); translocation control (animals were disturbed and moved from Fairlight to natural rock pools at Mrs Macquarie's Point) and transplanted animals (those that were disturbed, moved from Fairlight to Blackwattle Bay and placed in flowerpots). Fairlight was used as the control location in this experiment as Mrs Macquarie's Point was the closest rocky shore to Blackwattle Bay and this allowed the translocate and transplant treatments to be similarly distant from the control location (ca. 8 and $11 \mathrm{~km}$, respectively), which avoided potential confounding effects of geographic proximity on the interpretation of the behaviour of the animals. The design of this experiment allowed determination of whether the outcome was 
Pre-proof: Please see Morris, R.L., Martinez, A.S., Firth, L.B. and Coleman, R.A., 2018. Can transplanting enhance mobile marine invertebrates in ecologically engineered rock pools?. Marine Environmental Research 141: 119-127. https://www.sciencedirect.com/science/article/pii/S0141113618303404

caused by the disturbance of the animals, movement to a new location or movement to a new environment (Chapman, 1986).

Three of the most abundant species found in natural rock pools in Sydney Harbour were used in the experiment: the snails Bembicium nanum and Austrocochlea porcata and the starfish Parvulastra exigua. These species were either much less abundant (A. porcata) or absent from flowerpots (B. nanum and P. exigua) or the seawall (Table 1). Ten individuals of each species were transplanted in individual replicate groups $(30$ individuals $=3$ replicates in total), and the proportion (\%) of individuals remaining per group was used as the response variable. Starfish and snails at Fairlight were initially removed from replicate rock pools, tagged and placed back in their original pools for the control treatment. Snails were marked with shellfish tags and starfish were tagged using visible implant elastomer (Martinez et al., 2013). The control animals had to be disturbed to be tagged as it was not possible to mark individuals whilst underwater in rock pools. Therefore, tagging of control animals was done 24 hours prior to the start of the experiment to allow recovery from the disturbance, so at the start of the experiment they were considered undisturbed (Chapman, 1986; Underwood, 1977). Individuals in the other treatments were tagged the next day with different coloured tags. Animals from the disturbed treatment were tagged at Fairlight and placed back in the rock pool from which they were taken. Other marked animals were translocated or transplanted to natural or artificial rock pools at Mrs Macquarie's Point and Blackwattle Bay, respectively.

The following day, the number of marked individuals found in or out of rock pools or flowerpots were quantified. The experiment was repeated twice; the sites used at Fairlight were different each time because a relatively large number of animals needed to be collected 
Pre-proof: Please see Morris, R.L., Martinez, A.S., Firth, L.B. and Coleman, R.A., 2018. Can transplanting enhance mobile marine invertebrates in ecologically engineered rock pools?. Marine Environmental Research 141: 119-127. https://www.sciencedirect.com/science/article/pii/S0141113618303404

272

273

274

to translocate and transplant. The null hypothesis that the proportions of starfish and snails remaining in and out of pools were similar for all treatments were tested using a 3-way ANOVA (Treatment: 4 levels and orthogonal; Experimental run: 2 levels and random; Site: 2 levels, random and nested in experimental run) using GMAV5. When necessary, data were arcsine transformed to stabilise variances (Underwood, 1997).

\section{Results}

3.1. Passive approach: colonisation of flowerpots and rock pools

Of the 35 taxa found in total over 18 months, 25 were unique to natural rock pools and three were unique to flowerpots (Table 1). Of the seven species that were common to both habitats, the molluses: Austrocochlea porcata; Patelloida mimula; Siphonaria denticulata and an unidentified species of nudibranch had higher density in natural rock pools compared to flowerpots (Table 1). Conversely, Bedeva hanleyi, Bembicium auratum and fish were more abundant in flowerpots than natural rock pools, although the former two were already present on the seawall (Table 1). At the end of the end of the experiment, there was a significant effect of treatment on mobile species assemblage (PERMANOVA, Pseudo- $\mathrm{F}_{1,2}=$ $4.87, \mathrm{P}=0.03)$. Three taxa contributed more than $10 \%$ to the differences in the mobile assemblage between treatments: S. denticulata; B. auratum and A. porcata. Siphonaria denticulata and A. porcata were more abundant in natural rock pools, whereas B. auratum were more abundant in flowerpots (although this species was already present on the seawall, Table 1). Juveniles of some of the common grazing molluscs (Austrocochlea sp., Bembicium 
Pre-proof: Please see Morris, R.L., Martinez, A.S., Firth, L.B. and Coleman, R.A., 2018. Can transplanting enhance mobile marine invertebrates in ecologically engineered rock pools?. Marine Environmental Research 141: 119-127. https://www.sciencedirect.com/science/article/pii/S0141113618303404

293

294

295

296

297

298

299

300

301

302

303

304

305

306

307

308

309

310

311

312

sp., Cellana tramoserica and Siphonaria sp.) were recorded in rock pools, but not flowerpots (Table 1).

\subsection{Passive approach: recruitment to AUHs in flowerpots and rock pools}

Only four replicates for each time and treatment remained at the end of the study as AUHs were lost. Additionally, only data for the first 8 months of the study were available because AUHs were lost from rock pools due to storms during the last 4 months. A total of 149 individuals from 14 taxa were recorded from the three groups: molluscs (15 taxa), echinoderms (2 taxa) and decapods ( 1 taxon) (Table 2). Only two species recruited to the turf that were relevant to the hypotheses in this study (i.e. they were found in rock pools, but not in flowerpots or on the seawall), Austrolittorina unifasciata and Parvulastra exigua (Tables 1 and 2). Further, few recruits of these species were recorded and there was no significant difference between turf in rock pools compared to flowerpots (Table 2). Austrocochlea porcata and Parasesarma erythrodactyla were found as either adults or juveniles in rock pools and/or flowerpots (Experiment 1, Table 1), and as recruits in the turf (Table 2).

Parasesarma erythrodactyla was only found in flowerpots as adults, and only recruited to flowerpots rather than rock pools (Tables 1 and 2). Austrocochlea porcata was found in greater densities in rock pools, however, there were few recruits recorded in either habitat (Tables 1 and 2). The rest of the taxa that recruited to the AUHs were not found as adults in either rock pools or flowerpots (Tables 1 and 2). 
Pre-proof: Please see Morris, R.L., Martinez, A.S., Firth, L.B. and Coleman, R.A., 2018. Can transplanting enhance mobile marine invertebrates in ecologically engineered rock pools?. Marine Environmental Research 141: 119-127. https://www.sciencedirect.com/science/article/pii/S0141113618303404

314

315

316

317

318

\subsection{Active approach: transplantation experiment}

For Austrocochlea porcata, the proportion of snails found in flowerpots after transplantation was significantly less than all other treatments (Figure 3a; Table 3).

Nevertheless, there was also a significant effect of handling and location to which individuals were moved for A. porcata as the proportion of translocated individuals in pools was similar to the disturbance treatment, which were lower than the control (Figure 3a; Table 3). The proportion of animals found outside of flowerpots was greater than the proportions found outside of rock pools in the translocation treatment, and the control and disturbance treatments (Figure 3b; Table 3).

The proportion of $B$. nanum remaining in pools after one day varied across treatments for each experimental run (Figure 3a; Table 3). A lower proportion was found in flowerpots compared to the proportions of translocated and control snails at the first experimental run (Figure 3a). When the experiment was repeated, the proportion of B. nanum in locations where they were translocated (rock pools on natural shore) and transplanted (flowerpots on seawall) were similar and smaller compared to the control and disturbed treatments (Figure 3a). The proportion of $B$. nanum found outside of rock pools and flowerpots in the transplantation and translocation treatments was similar, and these were greater than the proportions of snails found for the control and disturbed treatments (Figure 3b; Table 3). 
Pre-proof: Please see Morris, R.L., Martinez, A.S., Firth, L.B. and Coleman, R.A., 2018. Can transplanting enhance mobile marine invertebrates in ecologically engineered rock pools?. Marine Environmental Research 141: 119-127. https://www.sciencedirect.com/science/article/pii/S0141113618303404

332

Note that the proportion of animals found in the disturbed treatment was lower than the control treatment, which suggests an effect of handling on B. nanum behaviour.

The behaviour of $P$. exigua was clearly affected by the transplantation; the proportion of $P$. exigua that remained in flowerpots was smaller than all treatments in natural rock pools (Figure 3a; Table 3). No P. exigua were found outside of rock pools or flowerpots.

\section{Discussion}

Here, we extend previous evaluation of water-retaining flowerpots on seawalls (Browne and Chapman, 2011; Browne and Chapman, 2014) by comparing colonisation and recruitment of mobile species to flowerpots with natural rock pools. Some species did recruit to the flowerpots that were not found on the seawall (e.g. fish, nudibranch). Of the species that were unique to natural rock pools (71\%), few recruits were recorded in the AUHs in either natural rock pools or in flowerpots. This suggests that the differences observed in the patterns of mobile species between rock pools and flowerpots, were likely due to dispersal of adults into rock pools from the surrounding emergent rock, rather than recruitment from the water column. As recruitment of common rock pool species was limited, the effectiveness of transplanting adults from natural shores to 'seed' the flowerpots was tested. The results for $B$. nanum were varied, with the proportion of individuals that stayed in flowerpots less than the other treatments for the first experimental run, but similar to those moved to rock pools in the second run. Similarly, the behaviour of Bembicium auratum varied among time and space in previous translocation experiments (Crowe and Underwood, 1999). In contrast, fewer $A$. 
Pre-proof: Please see Morris, R.L., Martinez, A.S., Firth, L.B. and Coleman, R.A., 2018. Can transplanting enhance mobile marine invertebrates in ecologically engineered rock pools?. Marine Environmental Research 141: 119-127. https://www.sciencedirect.com/science/article/pii/S0141113618303404

353

354

porcata and $P$. exigua remained in flowerpots than the other treatments, which suggests that flowerpots may not necessarily serve as a suitable habitat for these species.

Previous research has shown that intertidal species more frequently found in rock pools and other microhabitats that provide shelter are absent from artificial structures (Chapman, 2003; Moschella et al., 2005). Eco-engineered habitats can increase the number of species found on artificial structures in comparison to the surrounding habitat (e.g. Chapman and Underwood, 2011; Browne and Chapman, 2014; Firth et al., 2014a). Notably, some mobile species were reported in the initial evaluation of the flowerpots (Browne and Chapman, 2011) that were not recorded here. Obviously, this could be due to the many differences between the experiments, including type of pots and timing and location of pot deployment. Indeed, the mobile species assemblage found in flowerpots has been shown to be variable between locations (Browne and Chapman, 2014). Further, here the flowerpot and rock pool treatments were in different areas of the harbour and could have been influenced by other localised processes (e.g. water flow or exposure to wave action, Mullineaux and Butman, 1991; Firth et al., 2016b), separate from the effects of habitat. Unfortunately, location and habitat could not be un-confounded in this study because there was no permission to install the flowerpots onto seawalls where natural rocky shore was also present. Rock pools in different locations of Sydney Harbour, however, have the same common species present (Chapman and Blockley, 2009; Morris, 2016). Therefore, it could be expected that these species would also be present where the flowerpots were installed, if there was suitable habitat.

Few studies have made comparisons between eco-engineered and natural features (but see Chapman and Blockley, 2009; Evans et al. 2015). Even if the goal of the flowerpots was 
Pre-proof: Please see Morris, R.L., Martinez, A.S., Firth, L.B. and Coleman, R.A., 2018. Can transplanting enhance mobile marine invertebrates in ecologically engineered rock pools?. Marine Environmental Research 141: 119-127. https://www.sciencedirect.com/science/article/pii/S0141113618303404

376

to simply increase the biodiversity of seawalls rather than to exactly mimic rock pools, a comparison with the nearest natural equivalent is informative to understand what species can do well in eco-engineered habitats, and what species may be missing. This could instruct subsequent management objectives and/or future design of artificial rock pools. For instance, natural rock pools have great variability in aspects such as topography, volume and depth (Astles, 1993). Although, at least for mobile species, there has been little effect of rock pool diameter and slope on the emergent assemblage recorded (Underwood and Skilleter, 1996; Firth et al., 2014b), however, depth has been shown to influence the abundance of mobile species in some cases (Astles, 1993), but not others (Firth et al., 2014b). In accordance with one study that compared inbuilt cavities in seawalls to natural rock pools (Chapman and Blockley, 2009), flowerpots supported some, but not all mobile organisms found in rock pools. Conversely, the mobile species assemblage in drill-cored rock pools on a breakwater in the UK was not significantly different from that in nearby natural rock pools (Evans et al., 2015). The drill-cored rock pools were on a horizontal substratum, whereas flowerpots on seawalls differ from pools on natural rocky shores in that they are surrounded by vertical, rather than horizontal, substrata. Many species that use rock pools forage on the surrounding substrata when conditions allow (Underwood, 1977; Noël et al., 2009; Martinez et al., 2017). If these species cannot use the vertical habitat, then they may not be found in mimics of rock pools deployed on seawalls (Chapman and Blockley, 2009). Alternatively, recruitment processes may be responsible for the differences in assemblages, as colonisation of flowerpots relies on recruitment from the water column for those species that are not present on the seawall to disperse into flowerpots. 
Pre-proof: Please see Morris, R.L., Martinez, A.S., Firth, L.B. and Coleman, R.A., 2018. Can transplanting enhance mobile marine invertebrates in ecologically engineered rock pools?. Marine Environmental Research 141: 119-127. https://www.sciencedirect.com/science/article/pii/S0141113618303404

Here, there was little recruitment of mobile intertidal species to AUHs over 8 months in either flowerpots or natural rock pools. Prior studies have shown that artificial turf units are recruited to quickly by a large diversity and number of intertidal mobile species (Kelaher, 2005; Matias, 2013). In contrast to previous studies however, the AUHs in this study were deployed vertically, rather than horizontally, to the substratum. This was done as the predominant habitat in flowerpots was steeply sloping sides with a comparatively small surface area of horizontal base. Orientation of the substratum has been shown to influence patterns of biodiversity in some (Wendt et al., 1989; Glasby, 2000; Firth et al., 2014b), but not all (Firth et al., 2015) studies. Goldberg and Foster (2002) showed reduced recruitment of geniculate coralline algae to vertical seawalls in comparison to horizontal substrata. The method of deployment of artificial units of habitat can have an effect on the colonising gastropod assemblage (Chapman et al., 2008), although this has not been tested with regards to orientation. Testing the effect of orientation on mobile species recruitment could be done using further manipulative experiments. Furthermore, it is unknown whether different results would have been achieved using a different recruitment substratum (i.e. a sandstone or concrete tile). This research would give an insight into the factors affecting recruitment (e.g. orientation, material), and could be useful to inform the design of eco-engineered habitat features that may rely on recruitment for colonisation of species not found on the surrounding seawall.

It is likely that any species that are found in artificial rock pools, but not on the seawall have recruited there. Little or no recruitment may be enhanced through transplanting species from cultured or natural populations to artificial habitats prior or following installation (Perkol-Finkel et al., 2012; Strain et al., 2017). Previous studies (Perkol-Finkel et 
Pre-proof: Please see Morris, R.L., Martinez, A.S., Firth, L.B. and Coleman, R.A., 2018. Can transplanting enhance mobile marine invertebrates in ecologically engineered rock pools?. Marine Environmental Research 141: 119-127. https://www.sciencedirect.com/science/article/pii/S0141113618303404

al., 2012; Browne and Chapman, 2014) have not used all of the transplant controls (i.e. disturbance control and translocation) in the experiment, as done here. If the transplant fails, however, this is useful to determine what aspect of the transplantation affected the organisms i.e. disturbance, movement and/or artificial habitat, so methods may be revised in future experiments. For instance, for B. nanum movement to another location (i.e. translocation or transplantation), regardless of whether natural or artificial, may have an effect on the behaviour of this species. Conversely, the proportion of P. exigua and A. porcata that remained in the flowerpots was significantly smaller than the other treatments. This suggests that some aspect of the flowerpot habitat is not suitable for these organisms. Observations at high tide revealed that many of the starfish and snails left the flowerpots immediately when the water lapped the edge of the pots (Morris and Martinez, pers. obs.), and few or none returned the following day at low tide. Perhaps the vertical orientation of the seawall, and low percentage of flowerpot in comparison to seawall habitat makes it difficult for organisms to navigate back to the pots as the tide comes in. This seawall scale effect may particularly be the case for $A$. porcata as they were found in flowerpots on rare occasions naturally.

Therefore perhaps flowerpots would be suitable habitats if the percentage of flowerpot habitat relative to seawall was increased. For $P$. exigua, no individuals were recorded outside rock pools. This could be the result of mortality outside of natural or artificial rock pools, or due the difficulty of finding this species once it has left a rock pool, particularly amongst the oyster matrix on the seawall. Notably, B. nanum and A. porcata transplanted to flowerpots were seen inhabiting the seawall the following day. Whether these individuals can persist and reproduce over time on the seawall needs further study. 
Pre-proof: Please see Morris, R.L., Martinez, A.S., Firth, L.B. and Coleman, R.A., 2018. Can transplanting enhance mobile marine invertebrates in ecologically engineered rock pools?. Marine Environmental Research 141: 119-127. https://www.sciencedirect.com/science/article/pii/S0141113618303404

\section{Conclusion}

Our study has raised some important considerations for the management of marine infrastructure employing eco-engineering practices, in particular if the goal of ecoengineering is to mitigate the loss of natural habitats (Perkins et al., 2015). Future work should aim to further clarify the various processes contributing to colonisation of ecoengineered habitats using larger-scale, more robustly replicated experiments.

Transplantation is increasingly being used to promote the presence of native species on artificial structures, however the primary focus has been sessile habitat-forming organisms, such as corals, macroalgae, shellfish and sponges (Perkol-Finkel et al., 2012; Ng et al., 2015; Strain et al., 2017). Here, there was little recruitment of mobile intertidal species over the year in any habitat. Thus, differences between rock pools and flowerpots were likely due to the movement of adults between pools and the surrounding substratum, which cannot occur in flowerpots as these species are not found on the seawall. Whether there was a supply of larvae at the location where the flowerpots were installed and species were not recruiting, or there was no supply of larvae remains unknown. Larval traps could be used to determine whether larvae are in the water column, but not settling/recruiting or if they are absent around the flowerpots (Chen et al., 2013). Nevertheless, this study does highlight the importance of considering recruitment if the goal of eco-engineering is to achieve an assemblage similar to natural habitats, which may be relatively slow, or might never occur. This may be particularly the case for direct developers, which have lower dispersal than species with larval stages (Hoskin, 1997; Johnson et al., 2001; Barbosa et al., 2013). Here, only two invertebrates with direct development were seen, $P$. exigua and Bedeva hanleyi. B. hanleyi were already present on the seawall (Table 1), and P. exigua has been noted occasionally within the oyster matrix 
Pre-proof: Please see Morris, R.L., Martinez, A.S., Firth, L.B. and Coleman, R.A., 2018. Can transplanting enhance mobile marine invertebrates in ecologically engineered rock pools?. Marine Environmental Research 141: 119-127. https://www.sciencedirect.com/science/article/pii/S0141113618303404

467

on the wall (Morris, pers. obs.). Although, adults with direct development can disperse by floating or whilst attached to mobile substrata (e.g. wrack), known as rafting (Highsmith, 1985; Grantham et al., 2003). Further, it is not known whether the recruitment potential of a particular species is reduced if they are absent from a habitat for too long (Perkins et al., 2015). For example, recruitment of large numbers of sessile species can use all available space in a habitat, making it unavailable for later arriving grazing species (Underwood et al., 1983; Hawkins et al., 1992). Alternatively, some species will only settle in the presence of conspecifics (Sweatman, 1983; Gebauer et al., 2011). The transplant experiment showed, however, that even if species can recruit or if they are artificially seeded, eco-engineered habitats may have design limitations that makes them unsuitable for some species to persist. This research highlights the importance of manipulative experiments to disentangle the processes (recruitment and/or post-recruitment) in artificial systems. It is these processes that will determine the distribution of species colonising engineered features, and a good understanding is needed if we are to move forward in informing management of marine infrastructure.

\section{Acknowledgements}

We thank colleagues and volunteers at the Centre for Ecological Impacts of Coastal Cities for their field and lab assistance. M. G. Chapman is thanked for assistance with ideas, comments and evaluation of an earlier version of this manuscript. This study was funded by a City of Sydney Environmental Grant (to RLM and RAC) and a grant from The Sydney Coastal Councils Group, through funding from the Australian Government (to S. Golding, RAC, RLM and J. Martin). RLM was funded by a Britain-Australia PhD Studentship. ASM was 
Pre-proof: Please see Morris, R.L., Martinez, A.S., Firth, L.B. and Coleman, R.A., 2018. Can transplanting enhance mobile marine invertebrates in ecologically engineered rock pools?. Marine Environmental Research 141: 119-127. https://www.sciencedirect.com/science/article/pii/S0141113618303404

490

491

492

493

494

495

496

497

498

499

500

501

502

503

504

505

506

507

508

funded by Endeavour (Commonwealth of Australia, 2914_2012) and CNPq (Programa Ciências sem Fronteiras, 240918/2012-6) postgraduate scholarships. Research was done under Fisheries Permit P03/0029-4.1. We are grateful for the collaboration of S. Golding and City of Sydney Council.

\section{References}

Aguilera, M.A., Broitman, B.R., Thiel, M., 2014. Spatial variability in community composition on a granite breakwater versus natural rocky shores: Lack of microhabitats suppresses intertidal biodiversity. Mar. Pollut. Bull. 87, 257-268.

Anderson, M. J. 2001. A new method for non-parametric multivariate analysis of variance. Austral Ecol. 26, 32-46.

Anderson, M. J., Gorley, R. N., Clarke, K. R. 2008. PERMANOVA+ for PRIMER: Guide to software and statistical methods. PRIMER-E, Plymouth, UK.

Astles, K.L., 1993. Patterns of abundance and distribution of species in intertidal rock pools. J. Mar. Biol. Assoc. U.K. 73, 555-569.

Barbosa, S.S., Klanten, S.O., Puritz, J.B., Toonen, R.J., Byrne, M., 2013. Very fine-scale population genetic structure of sympatric asterinid sea stars with benthic and pelagic larvae: Influence of mating system and dispersal potential. Biol. J. Linn. Soc. 108, 821-833.

Bishop, M.J., Mayer-Pinto, M., Airoldi, L., Firth, L.B., Morris, R.L., Loke, L.H.L., Hawkins, S.J., Naylor, L.A., Coleman, R.A., Chee, S.Y., Dafforn, K.A., 2017. Effects of ocean sprawl on ecological connectivity: impacts and solutions. J. Exp. Mar. Biol. Ecol.

Blockley, D.J., Chapman, M.G., 2006. Recruitment determines differences between assemblages on shaded or unshaded seawalls. Mar. Ecol. Prog. Ser. 327, 27-36. 
Pre-proof: Please see Morris, R.L., Martinez, A.S., Firth, L.B. and Coleman, R.A., 2018. Can transplanting enhance mobile marine invertebrates in ecologically engineered rock pools?. Marine Environmental Research 141: 119-127. https://www.sciencedirect.com/science/article/pii/S0141113618303404

513

Blockley, D.J., Chapman, M.G., 2008. Exposure of seawalls to waves within an urban estuary: Effects on intertidal assemblages. Austral Ecol. 33, 168-183.

Bracewell, S.A., Robinson, L.A., Firth, L.B., Knights, A.M., 2013. Predicting free-space occupancy on novel artificial structures by an invasive intertidal barnacle using a removal experiment. PLoS One 8, e74457. doi:74410.71371/journal.pone.0074457.

Browne, M.A., Chapman, M.G., 2011. Ecologically informed engineering reduces loss of intertidal biodiversity on artificial shorelines. Environ. Sci. Technol. 45, 8204-8207.

Browne, M.A., Chapman, M.G., 2014. Mitigating against the loss of species by adding artificial intertidal pools to existing seawalls. Mar. Ecol. Prog. Ser. 497, 119-129.

Bulleri, F., 2005. Role of recruitment in causing differences between intertidal assemblages on seawalls and rocky shores. Mar. Ecol. Prog. Ser. 287, 53-64.

Bulleri, F., Chapman, M.G., 2004. Intertidal assemblages on artificial and natural habitats in marinas on the north-west coast of Italy. Mar. Biol. 145, 381-391.

Bulleri, F., Chapman, M.G., 2010. The introduction of coastal infrastructure as a driver of change in marine environments. J. Appl. Ecol. 47, 26-35.

Bulleri, F., Chapman, M.G., Underwood, A.J., 2005. Intertidal assemblages on seawalls and vertical rocky shores in Sydney Harbour, Australia. Austral Ecol. 30, 655-667.

Chapman, M.G., 1986. Assessment of some controls in experimental transplants of intertidal gastropods. J. Exp. Mar. Biol. Ecol. 103, 181-201.

Chapman, M.G., 2003. Paucity of mobile species on constructed seawalls: Effects of urbanization on biodiversity. Mar. Ecol. Prog. Ser. 264, 21-29.

Chapman, M.G., Blockley, D.J., 2009. Engineering novel habitats on urban infrastructure to increase intertidal biodiversity. Oecologia 161, 625-635. 
Pre-proof: Please see Morris, R.L., Martinez, A.S., Firth, L.B. and Coleman, R.A., 2018. Can transplanting enhance mobile marine invertebrates in ecologically engineered rock pools?. Marine Environmental Research 141: 119-127. https://www.sciencedirect.com/science/article/pii/S0141113618303404

536

537

Chapman, M.G., People, J., Blockley, D., 2005. Intertidal assemblages associated with natural corallina turf and invasive mussel beds. Biodivers. Conserv. 14, 1761-1776.

Chapman, M.G., Underwood, A.J., 1992. Experimental designs for the analyses of movements by molluses, Proceedings of the Third International Symposium on Littorinid Biology. The Malacological Society of London, pp. 169-180.

Chapman, M.G., Underwood, A.J., 2011. Evaluation of ecological engineering of "armoured" shorelines to improve their value as habitat. J. Exp. Mar. Biol. Ecol. 400, 302-313.

Chapman, M.G., Underwood, A.J., Blockley, D., 2008. Effects of method of deployment of artificial units of habitat on microgastropod colonization. Mar. Ecol. Prog. Ser. 366, 49-57. Chee, S.Y., Othman, A.G., Sim, Y.K., Mat Adam, A.N., Firth, L.B., 2017. Land reclamation and artificial islands: Walking the tightrope between development and conservation. Glob. Ecol. and Conserv. 12, 80-95.

Chen, H.-N., Todd, C.D., Williams, G.A., Chan, B.K.K., 2013. A new passive plankton trap to quantify the supply of crustacean and molluscan larvae to rocky shores. J. Exp. Mar. Biol. Ecol. 441, 80-89.

Clarke, K. R. 1993. Nonparametric multivariate analyses of changes in community structure. Aust. J. Ecol. 18, 117-143.

Connell, S.D., Glasby, T.M., 1999. Do urban structures influence local abundance and diversity of subtidal epibiota? A case study from Sydney Harbour, Australia. Mar. Environ. Res. 47, 373-387.

Coombes, M.A., La Marca, E.C., Naylor, L.A., Thompson, R.C., 2015. Getting into the groove: Opportunities to enhance the ecological value of hard coastal infrastructure using fine-scale surface textures. Ecol. Eng. 77, 314-323. 
Pre-proof: Please see Morris, R.L., Martinez, A.S., Firth, L.B. and Coleman, R.A., 2018. Can transplanting enhance mobile marine invertebrates in ecologically engineered rock pools?. Marine Environmental Research 141: 119-127. https://www.sciencedirect.com/science/article/pii/S0141113618303404

559

560

561

562

Crowe, T.P., Underwood, A.J., 1999. Differences in dispersal of an intertidal gastropod in two habitats: the need for and design of repeated experimental transplantation. J. Exp. Mar. Biol. Ecol. 237, 31-60.

Dafforn, K.A., Glasby, T.M., Airoldi, L., Rivero, N.K., Mayer-Pinto, M., Johnston, E.L., 2015a. Marine urbanization: An ecological framework for designing multifunctional artificial structures. Front. Ecol. Environ. 13, 82-90.

Dafforn, K.A., Mayer-Pinto, M., Morris, R.L., Waltham, N.J., 2015b. Application of management tools to integrate ecological principles with the design of marine infrastructure. J. Environ. Manage. 158, 61-73.

Davis, J.L.D., Levin, L.A., Walther, S.M., 2002. Artificial armored shorelines: sites for opencoast species in a southern California bay. Mar. Biol. 140, 1249-1262.

Dugan, J.E., Airoldi, L., Chapman, M.G., Walker, S.J., Schlacher, T., 2011. Estuarine and coastal structures: Environmental effects, a focus on shore and nearshore structures, in:

Wolanski, E., McLusky, D. (Eds.), Treatise on Estuarine and Coastal Science, Vol 8: HumanInduced Problems. Elsevier, United Kingdom, pp. 17-41.

Evans, A.J., Firth, L.B., Hawkins, S.J., Morris, E.S., Goudge, H., Moore, P.J., 2015. Drillcored rock pools: An effective method of ecological enhancement on artificial structures. Mar. Freshwater Res. 67, 123-130.

Firth, L.B., Knights, A.M., Bridger, D., Evans, A.J., Mieszkowska, N., Moore, P., O'Connor, N.E., Sheehan, E., Thompson, R.C., Hawkins, S.J., 2016a. Ocean sprawl: Challenges and opportunities for biodiversity management in a changing world. Oceanogr. Mar. Biol. Annu. Rev. 54:189-262 
Pre-proof: Please see Morris, R.L., Martinez, A.S., Firth, L.B. and Coleman, R.A., 2018. Can transplanting enhance mobile marine invertebrates in ecologically engineered rock pools?. Marine Environmental Research 141: 119-127. https://www.sciencedirect.com/science/article/pii/S0141113618303404

581

582

583

584

585

586

587

588

589

590

591

592

593

594

595

596

597

598

599

600

601

602

603

Firth, L.B., Browne, K.A., Knights, A.M., Hawkins, S.J., Nash, R., 2016b. Eco-engineered rock pools: a concrete solution to biodiversity loss and urban sprawl in the marine environment. Environ. Res. Lett. 11, 094015.

Firth, L.B., Thompson, R.C., Bohn, K., Abbiati, M., Airoldi, L., Bouma, T.J., Bozzeda, F., Ceccherelli, V.U., Colangelo, M.A., Evans, A., Ferrario, F., Hanley, M.E., Hinz, H., Hoggart, S.P.G., Jackson, J.E., Moore, P., Morgan, E.H., Perkol-Finkel, S., Skov, M.W., Strain, E.M., van Belzen, J., Hawkins, S.J., 2014a. Between a rock and a hard place: Environmental and engineering considerations when designing coastal defence structures. Coast. Eng. 87, 122135.

Firth, L.B., Schofield, M., White, F.J., Skov, M.W., Hawkins, S.J., 2014b. Biodiversity in intertidal rock pools: Informing engineering criteria for artificial habitat enhancement in the built environment. Mar. Environ. Res. 102, 122-130.

Firth, L.B., Thompson, R.C., White, F.J., Schofield, M., Skov, M.W., Hoggart, S.P.G., Jackson, J., Knights, A.M., Hawkins, S.J., 2013. The importance of water-retaining features for biodiversity on artificial intertidal coastal defence structures. Divers. Distrib. 19, 12751283.

Firth, L.B., White, F.J., Schofield, M., Hanley, M.E., Burrows, M.T., Thompson, R.C., Skov, M.W., Evans, A.J., Moore, P.J., Hawkins, S.J., 2015. Facing the future: The importance of substratum features for ecological engineering of artificial habitats in the rocky intertidal. Mar. Freshwater Res. 67, 131-143.

Gebauer, P., Freire, M., Barria, A., Paschke, K., 2011. Effect of conspecifics density on the settlement of Petrolisthes laevigatus (Decapoda: Porcellanidae). J. Mar. Biol. Assoc. U.K. 91, 1453-1458. 
Pre-proof: Please see Morris, R.L., Martinez, A.S., Firth, L.B. and Coleman, R.A., 2018. Can transplanting enhance mobile marine invertebrates in ecologically engineered rock pools?. Marine Environmental Research 141: 119-127. https://www.sciencedirect.com/science/article/pii/S0141113618303404

604

605

606

607

608

609

610

611

612

613

614

615

616

617

618

619

620

621

622

623

624

625

626

Gittman, R.K., Fodrie, F.J., Popowich, A.M., Keller, D.A., Bruno, J.F., Currin, C.A., Peterson, C.H., Piehler, M.F., 2015. Engineering away our natural defenses: an analysis of shoreline hardening in the US. Front. Ecol. Environ. 13, 301-307.

Glasby, T.M., 2000. Surface composition and orientation interact to affect subtidal epibiota. J. Exp. Mar. Biol. Ecol. 248, 177-190.

Goldberg, N.A., Foster, M.S., 2002. Settlement and post-settlement processes limit the abundance of the geniculate coralline alga Calliarthron on subtidal walls. J. Exp. Mar. Biol. Ecol. 278, 31-45.

Goodsell, P.J., Chapman, M.G., Underwood, A.J., 2007. Differences between biota in anthropogenically fragmented habitats and in naturally patchy habitats. Mar. Ecol. Prog. Ser. $351,15-23$.

Grantham, B.A., Eckert, G.L., Shanks, A.L., 2003. Dispersal potential of marine invertebrates in diverse habitats. Ecol. Appl. 13, 108-116.

Hawkins, S.J., Hartnoll, R.G., Kain, J.M., Norton, T.A., 1992. Plant-animal interactions on hard substrata in the north-east Atlantic, in: John, D.M., Hawkins, S.J., Price, J.H. (Eds.), Plant-Animal Interactions in the Marine Benthos. Clarendon Press, United Kingdom, pp. 132.

Heery, E.C., Bishop, M.J., Critchley, L., Bugnot, A.B., Airoldi, L., Mayer-Pinto, M., Sheehan, E.V., Coleman, R.A., Loke, L.H.L., Johnston, E.L., Komyakova, V., Morris, R.L., Strain, E.M.A., Naylor, L.A., Dafforn, K.A., 2017. Identifying the consequences of ocean sprawl for sedimentary habitats. J. Exp. Mar. Biol. Ecol. 492, 31-48.

Highsmith, R.C., 1985. Floating and algal rafting as potential dispersal mechanisms in brooding invertebrates. Mar. Ecol. Prog. Ser. 25, 169-179. 
Pre-proof: Please see Morris, R.L., Martinez, A.S., Firth, L.B. and Coleman, R.A., 2018. Can transplanting enhance mobile marine invertebrates in ecologically engineered rock pools?. Marine Environmental Research 141: 119-127. https://www.sciencedirect.com/science/article/pii/S0141113618303404

627

628

629

630

631

632

633

634

635

636

637

638

639

640

641

642

643

644

645

646

647

648

649

Hoskin, M.G., 1997. Effects of contrasting modes of larval development on the genetic structures of populations of three species of prosobranch gastropods. Mar. Biol. 127, 647656.

Iveša, L., Chapman, M.G., Underwood, A.J., Murphy, R.J., 2010. Differential patterns of distribution of limpets on intertidal seawalls: Experimental investigation of the roles of recruitment, survival and competition. Mar. Ecol. Prog. Ser. 407, 55-69.

Jackson, A.C., Chapman, M.G., Underwood, A.J., 2008. Ecological interactions in the provision of habitat by urban development: Whelks and engineering by oysters on artificial seawalls. Austral Ecol. 33, 307-316.

Johnson, M.P., Allcock, A.L., Pye, S.E., Chambers, S.J., Fitton, D.M., 2001. The effects of dispersal mode on the spatial distribution patterns of intertidal molluscs. J. Anim. Ecol. 70, 641-649.

Kelaher, B.P., 2005. Does colonization contribute to spatial patterns of common invertebrates in coralline algal turf? Austral Ecol. 30, 40-48.

Knights, A.M., Firth, L.B., Walters, K., 2012. Interactions between Multiple Recruitment Drivers: Post-Settlement Predation Mortality and Flow-Mediated Recruitment. Plos One 7, e35096.

Kohler, J., Hansen, P.D., Wahl, M., 1999. Colonization patterns at the substratum-water interface: How does surface microtopography influence recruitment patterns of sessile organisms? Biofouling 14, 237-248.

Lam, N.W.Y., Huang, R., Chan, B.K.K., 2009. Variations in intertidal assemblages and zonation patterns between vertical artificial seawalls and natural rocky shores: A case study from Victoria Harbour, Hong Kong. Zool. Stud. 48, 184-195. 
Pre-proof: Please see Morris, R.L., Martinez, A.S., Firth, L.B. and Coleman, R.A., 2018. Can transplanting enhance mobile marine invertebrates in ecologically engineered rock pools?. Marine Environmental Research 141: 119-127. https://www.sciencedirect.com/science/article/pii/S0141113618303404

650

651

652

653

654

655

656

657

658

659

660

661

662

663

664

665

666

667

668

669

670

671

672

MacLulich, J.H. 1986. Colonization of bare rock surfaces by microflora in a rocky intertidal habitat. Mar. Ecol. Prog. Ser. 32, 91-96.

Martinez, A.S., Byrne, M., Coleman, R.A., 2013. Unique tagging of small echinoderms: a case study using the cushion star Parvulastra exigua. Methods Ecol. Evol. 4, 993-1000.

Martinez, A.S., Queiroz, E.V., Bryson, M., Byrne, M., Coleman, R.A., 2017. Incorporating in situ habitat patchiness in site selection models reveals that site fidelity is not always a consequence of animal choice. J. Anim. Ecol. 86, 847-856.

Matias, M., 2013. Macrofaunal responses to structural complexity are mediated by environmental variability and surrounding habitats. Mar. Biol. 160, 493-502.

McGrath, D., King, P.A., Reidy, M., 1994. Conditioning of artificial substrata and settlement of the marine mussel Mytilus edulis L.: A field experiment. Biol. Environ. 94B, 53-56.

McManus, R.S., Archibald, N., Comber, S., Knights, A.M., Thompson, R.C., Firth, L.B., in press. Partial replacement of cement for waste aggregates in concrete coastal and marine infrastructure: A foundation for ecological enhancement? Ecol. Eng. DOI:

10.1016/j.ecoleng.2017.06.062

Moreira, J., Chapman, M.G., Underwood, A.J., 2007. Maintenance of chitons on seawalls using crevices on sandstone blocks as habitat in Sydney Harbour, Australia. J. Exp. Mar. Biol. Ecol. 347, 134-143.

Morris, R.L., 2016. Retrofitting biodiversity: ecological engineering for management of urbanised systems. University of Sydney, Australia.

Morris, R.L., Chapman, M.G., Firth, L.B., Coleman, R.A., 2017. Increasing habitat complexity on seawalls: Investigating large- and small-scale effects on fish assemblages.

Ecol. Evol. 7, 9567-9579. 
Pre-proof: Please see Morris, R.L., Martinez, A.S., Firth, L.B. and Coleman, R.A., 2018. Can transplanting enhance mobile marine invertebrates in ecologically engineered rock pools?. Marine Environmental Research 141: 119-127. https://www.sciencedirect.com/science/article/pii/S0141113618303404

673

Morris, R.L., Golding, S., Dafforn, K.A., Coleman, R.A., in press. Can coir increase native biodiversity and reduce colonisation of non-indigenous species in eco-engineered rock pools? Ecol. Eng. DOI: 10.1016/j.ecoleng.2017.06.038

Moschella, P.S., Abbiati, M., Aberg, P., Airoldi, L., Anderson, J.M., Bacchiocchi, F., Bulleri, F., Dinesen, G.E., Frost, M., Gacia, E., Granhag, L., Jonsson, P.R., Satta, M.P., Sundelof, A., Thompson, R.C., Hawkins, S.J., 2005. Low-crested coastal defence structures as artificial habitats for marine life: Using ecological criteria in design. Coast. Eng. 52, 1053-1071. Mullineaux, L.S., Butman, C.A., 1991. Initial contact, exploration and attachment of barnacle (Balanus amphitrite) cyprids settling in flow. Mar. Biol. 110, 93-103.

Murphy, R.J. \& Underwood, A.J. 2006. Novel use of digital colour-infrared imagery to test hypotheses about grazing by intertidal herbivorous gastropods. J. Exp. Mar. Biol. Ecol. 330, 437-447.

Ng, C.S.L., Lim, S.C., Ong, J.Y., Teo, L.M.S., Chou, L.M., Chua, K.E., Tan, K.S., 2015. Enhancing the biodiversity of coastal defence structures: Transplantation of nursery-reared reef biota onto intertidal seawalls. Ecol. Eng. 82, 480-486.

Noël, L.M.L.J., Hawkins, S.J., Jenkins, S.R., Thompson, R.C., 2009. Grazing dynamics in intertidal rockpools: Connectivity of microhabitats. J. Exp. Mar. Biol. Ecol. 370, 9-17. Palmer, M.A., Ambrose, R.F., Poff, N.L., 2008. Ecological Theory and Community Restoration Ecology. Restor. Ecol. 5, 291-300.

Perkins, M.J., Ng, T.P.T., Dudgeon, D., Bonebrake, T.C., Leung, K.M.Y., 2015. Conserving intertidal habitats: What is the potential of ecological engineering to mitigate impacts of coastal structures? Estuar. Coast. Shelf Sci. 167, 504-515. 
Pre-proof: Please see Morris, R.L., Martinez, A.S., Firth, L.B. and Coleman, R.A., 2018. Can transplanting enhance mobile marine invertebrates in ecologically engineered rock pools?. Marine Environmental Research 141: 119-127. https://www.sciencedirect.com/science/article/pii/S0141113618303404

695

696

697

698

699

700

701

702

703

704

705

706

707

708

709

710

711

712

713

714

715

Perkol-Finkel, S., Ferrario, F., Nicotera, V., Airoldi, L., 2012. Conservation challenges in urban seascapes: Promoting the growth of threatened species on coastal infrastructures. J. Appl. Ecol. 49, 1457-1466.

Sokal, R.R., Rohlf, F.J., 2012. Biometry, the Principles and Practice of Statistics on

Biological Research. W. H. Freeman and Company, United States.

Strain, E., Olabarria, C., Mayer-Pinto, M., Cumbo, V., Morris, R., Bugnot, A., Dafforn, K., Heery, E., Firth, L., Brooks, P., Bishop, M., 2018. Eco-engineering built infrastructure for marine and coastal biodiversity: which interventions have the greatest ecological benefit? J. Appl. Ecol. 55, 426-441.

Strain, E.M., Morris, R.L., Coleman, R.A., Figueira, W.F., Steinberg, P.D., Johnston, E.L., Bishop, M.J., 2017. Increasing microhabitat complexity on seawalls can reduce fish predation on native oysters Ecol. Eng. DOI: 10.1016/j.ecoleng.2017.05.030.

Sweatman, H.P.A., 1983. Influence of conspecifics on choice of settlement sites by larvae of two pomacentrid fishes (Dascyllus aruanus and D. reticulatus) on coral reefs. Mar. Biol. 75, 225-229.

Underwood, A.J., 1976. Analysis of patterns of dispersion of intertidal prosobranch gastropods in relation to macroalgae and rock-pools. Oecologia 25, 145-154.

Underwood, A.J., 1977. Movements of intertidal gastropods. J. Exp. Mar. Biol. Ecol. 26, 191-201.

Underwood, A.J., 1997. Experiments in Ecology: Their Logical Design and Interpretation Using Analysis of Variance. Cambridge University Press. U. K. 
Pre-proof: Please see Morris, R.L., Martinez, A.S., Firth, L.B. and Coleman, R.A., 2018. Can transplanting enhance mobile marine invertebrates in ecologically engineered rock pools?. Marine Environmental Research 141: 119-127. https://www.sciencedirect.com/science/article/pii/S0141113618303404

716 Underwood, A.J., Denley, E.J., Moran, M.J., 1983. Experimental analyses of the structure

717 and dynamics of mid-shore rocky intertidal communities in New South Wales. Oecologia 56, $718 \quad 202-219$.

719 Underwood, A.J., Fairweather, P.G., 1989. Supply-side ecology and benthic marine assemblages. Trends Ecol. Evol. 4, 16-20.

721 Underwood, A.J., Skilleter, G.A., 1996. Effects of patch-size on the structure of assemblages in rock pools. J. Exp. Mar. Biol. Ecol. 197, 63-90.

Walls, A., Edwards, M., Firth, L., Johnsen, M., In review. Ecological priming of artificial aquaculture structures: Kelp farms as an example. J. Mar. Biol. Assoc. U. K. 
Pre-proof: Please see Morris, R.L., Martinez, A.S., Firth, L.B. and Coleman, R.A., 2018. Can transplanting enhance mobile marine invertebrates in ecologically engineered rock pools?. Marine Environmental Research 141: 119-127. https://www.sciencedirect.com/science/article/pii/S0141113618303404

741 Table 1. Summary of the taxa found over 18 months (18 surveys) in rock pools (RP) and

742 flowerpots (FP). Taxa are indicated as not present (-) or present (+). Taxa indicated as not

743 present or present on the seawall (SW) are listed from surveys before and after the installation of the pots ( 3 sampling times before and after, $n=12$; Morris, 2016).

\begin{tabular}{|c|c|c|c|c|}
\hline & & $\mathbf{R P}$ & FP & SW \\
\hline Amphipods & Caprellid spp. & + & - & - \\
\hline \multirow[t]{5}{*}{ Decapods } & Crab sp. 1 & + & - & - \\
\hline & Crab sp. 2 & + & - & - \\
\hline & Crab sp. 3 & + & - & - \\
\hline & Parasesarma erythrodactyla & - & + & + \\
\hline & Shrimp sp. 1 & + & - & - \\
\hline Echinoderms & *Parvulastra exigua & + & - & - \\
\hline Fish & Fish spp. & + & + & - \\
\hline \multirow[t]{22}{*}{ Molluses } & Acanthochitona sp. & + & - & - \\
\hline & Afrolittorina acutispira & + & - & + \\
\hline & Austrocochlea porcata & + & + & - \\
\hline & Austrocochlea juvenile & + & - & - \\
\hline & Austrolittorina unifasciata & + & - & - \\
\hline & *Bedeva hanleyi & - & + & + \\
\hline & Bembicium auratum & + & + & + \\
\hline & Bembicium nanum & + & - & $+\dagger$ \\
\hline & Bembicium juvenile & + & - & - \\
\hline & Cellana tramoserica & + & - & + \\
\hline & Cellana tramoserica juvenile & + & - & - \\
\hline & Montfortula rugosa & + & - & - \\
\hline & Morula marginalba & + & - & + \\
\hline & Nudibranch sp. 1 & + & + & - \\
\hline & Nudibranch sp. 2 & + & - & - \\
\hline & Onchidella patelloides & + & - & - \\
\hline & Patelloida alticostata & + & - & - \\
\hline & Patelloida mimula & + & + & + \\
\hline & Sea slug sp. 1 & + & - & - \\
\hline & Siphonaria denticulata & + & + & + \\
\hline & Siphonaria virgulata & + & - & - \\
\hline & Siphonariid juvenile & + & - & - \\
\hline
\end{tabular}




\begin{tabular}{lllll} 
& Sypharochiton pelliserpentis & + & - & + \\
& Unidentified juvenile limpet & + & - & - \\
Nematodes & Nematode sp. 1 & - & + & - \\
Platyhelminthes & Cream platyhelminth & + & + & - \\
Polychaetes & Polychaete sp. 1 & + & - & - \\
\hline
\end{tabular}

*Invertebrates with direct development

$\dagger$ One individual found

745 Table 2. $\chi^{2}$ tests for the number of taxa summed over 8 months comparing taxa that had

746 recruited to artificial units of habitat in rock pools (RP) and flowerpots (FP). Taxa in bold

747 indicate those taxa there were specific hypotheses about. Statistical tests underlined indicate a

748 binomial test was used, $\mathrm{df}=1 . * \mathrm{P}<0.05, * * \mathrm{P}<0.01, * * * \mathrm{P}<0.001$

\begin{tabular}{llrrc} 
& & RP & FP & $\chi^{\mathbf{2}}$ \\
\hline Decapod & Parasesarma erythrodactyla & 0 & 71 & $71.0^{* * *}$ \\
Echinoderm & Ophiuroid & 1 & 3 & $\underline{\mathrm{ns}}$ \\
& Parvulastra exigua & 3 & 1 & $\underline{\mathrm{ns}}$ \\
& Austrocochlea porcata & 2 & 0 & $\underline{\mathrm{ns}}$ \\
& Austrolittorina unifasciata & 2 & 0 & $\underline{\mathrm{ns}}$ \\
& Bivalve 8 & 0 & 6 & $6.0^{* *}$ \\
& Cantharidella sp. & 1 & 0 & $\underline{\mathrm{ns}}$ \\
& Columbellidae & 0 & 1 & $\underline{\mathrm{ns}}$ \\
& Hiatella australis & 8 & 28 & $11.1^{* * *}$ \\
& Muricidae & 0 & 2 & $\underline{\mathrm{ns}}$ \\
& Pectinidae & 1 & 3 & $\underline{\mathrm{ns}}$ \\
& Tawera lagopus & 0 & 13 & $13.0^{* * *}$ \\
& Turridae & 0 & 1 & $\underline{\mathrm{ns}}$ \\
& Veneridae & 1 & 1 & $\underline{\mathrm{ns}}$ \\
\hline
\end{tabular}


762 Table 3: ANOVA results of the proportion of snails and starfish found in or out of pools from 763 the transplant experiment. Data were arcsin transformed to reach the assumption of 764 homogeneity of variances when necessary. Interaction terms were eliminated when the $P$ 765 values were greater than 0.25 (Underwood 1997). Post hoc SNK test are shown for significant 766 factors.

\begin{tabular}{|c|c|c|c|c|c|c|c|c|}
\hline \multirow{3}{*}{$\begin{array}{l}\text { Austrocochlea porcata } \\
\text { Source }\end{array}$} & & \multicolumn{3}{|c|}{ Proportion in pools } & \multicolumn{4}{|c|}{ Proportion outside pools } \\
\hline & & \multicolumn{3}{|c|}{$\left(\right.$ Cochran's $\left.C=0.200^{n s}\right)$} & & \multicolumn{3}{|c|}{$(\text { Cochran's } C=0.336)^{*}$} \\
\hline & $d f$ & MS & $F$ & $P$ & & MS & $F$ & $P$ \\
\hline Treatment $\operatorname{Tr}$ & 3 & 0.8203 & 37.46 & $<0.001$ & & 1341.4681 & 11.52 & $<0.05$ \\
\hline Experimental run Er & 1 & 0.0133 & 0.10 & $>0.05$ & & 38.7768 & 0.10 & $>0.05$ \\
\hline Site $\mathrm{Si}(\mathrm{Er})$ & 2 & 0.1321 & 6.04 & $<0.01$ & \multicolumn{2}{|r|}{373.0947} & 2.67 & $>0.05$ \\
\hline $\operatorname{Tr} x \operatorname{Er}$ & 3 & \multicolumn{3}{|c|}{ eliminated } & & 116.4674 & 0.60 & $>0.05$ \\
\hline $\operatorname{Tr} \times \mathrm{Si}(\mathrm{Er})$ & 6 & \multicolumn{3}{|c|}{ eliminated } & \multicolumn{2}{|r|}{195.2007} & 1.40 & $>0.05$ \\
\hline \multirow[t]{4}{*}{ RES } & 32 & & & & \multicolumn{4}{|c|}{139.5776} \\
\hline & $\operatorname{Tr}$ & \multicolumn{3}{|c|}{$\mathrm{TP}<\mathrm{TL}=\mathrm{DC}<\mathrm{C}$} & $\operatorname{Tr}$ & $\mathrm{C}=\mathrm{DC}=\mathrm{Tl}$ & $<\mathrm{TP}$ & \\
\hline & $\mathrm{Si}(\mathrm{Er})$ & \multicolumn{3}{|c|}{ ER 1: S1 = S2 } & & & & \\
\hline & & \multicolumn{3}{|c|}{ ER 2: S2 $<$ S1 } & & & & \\
\hline \multicolumn{2}{|l|}{ Bembicium nanum } & \multicolumn{3}{|c|}{$\left(\right.$ Cochran's $\left.C=0.115^{n s}\right)$} & & \multicolumn{3}{|c|}{$\left(\right.$ Cochran's $\left.C=0.175^{n s}\right)$} \\
\hline Source & $d f$ & MS & $F$ & $P$ & & MS & $F$ & $P$ \\
\hline Treatment $\operatorname{Tr}$ & 3 & 0.5311 & 4.56 & $>0.05$ & & 0.3485 & 13.94 & $<0.001$ \\
\hline Experimental run Er & 1 & 0.0675 & 32.4 & $<0.05$ & & 0.1102 & 12.9 & $>0.05$ \\
\hline Site Si (Er) & 2 & 0.0021 & 0.09 & $>0.05$ & & 0.0085 & 0.34 & $>0.05$ \\
\hline $\operatorname{Tr} \mathrm{x} E r$ & 3 & 0.1164 & 4.95 & $<0.01$ & & \multicolumn{3}{|l|}{ eliminated } \\
\hline $\operatorname{Tr} \times \mathrm{Si}(\mathrm{Er})$ & 6 & \multicolumn{3}{|c|}{ eliminated } & & \multicolumn{3}{|l|}{ eliminated } \\
\hline \multirow{4}{*}{ NK result } & 32 & \multicolumn{3}{|l|}{0.0235} & & \multicolumn{3}{|l|}{0.0250} \\
\hline & $\mathrm{Er}$ & \multicolumn{3}{|l|}{$1<2$} & & \multirow[t]{3}{*}{$\operatorname{Tr}$} & $<\mathrm{TL}=$ & \\
\hline & $\operatorname{Tr} x \operatorname{Er}$ & \multicolumn{3}{|c|}{ ER1: $\mathrm{TP}<\mathrm{TL}=\mathrm{DC}=\mathrm{C}$} & & & & \\
\hline & & \multicolumn{3}{|c|}{$\mathrm{ER} 2: \mathrm{TP}=\mathrm{TL}<\mathrm{DC}=\mathrm{C}$} & & & & \\
\hline
\end{tabular}




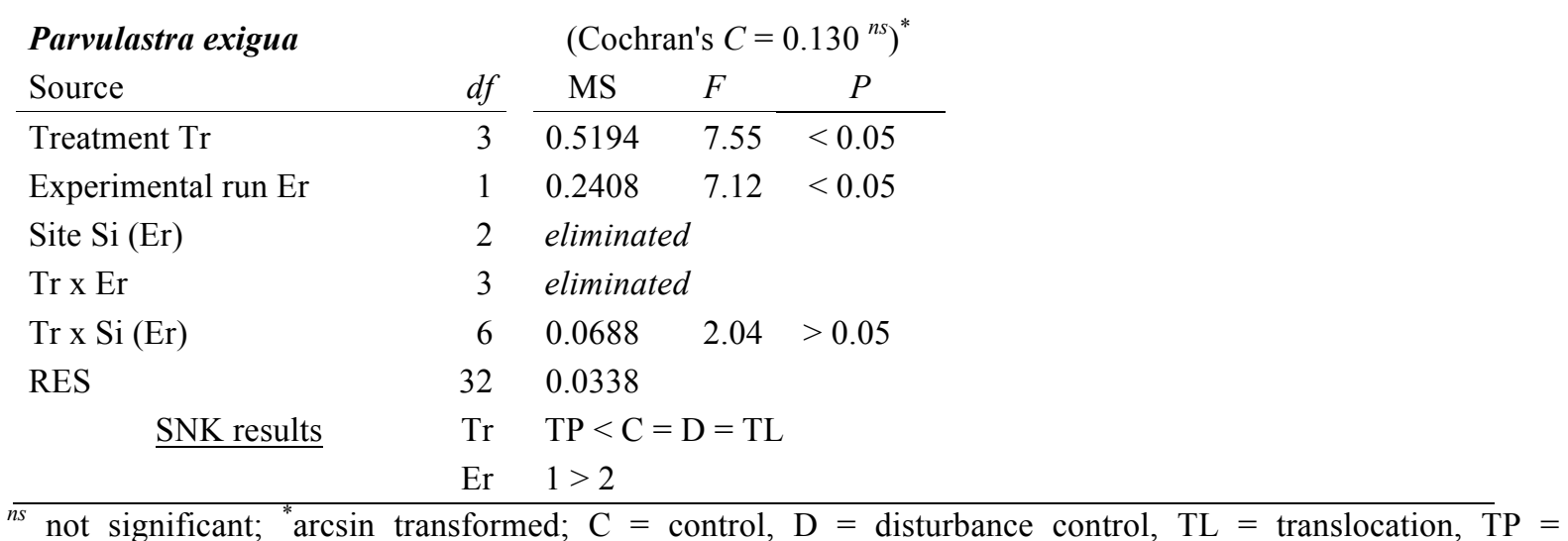

Parvulastra exigua were not observed outside of rock pools or flowerpots. 
Pre-proof: Please see Morris, R.L., Martinez, A.S., Firth, L.B. and Coleman, R.A., 2018. Can transplanting enhance mobile marine invertebrates in ecologically engineered rock pools?. Marine Environmental Research 141: 119-127. https://www.sciencedirect.com/science/article/pii/S0141113618303404

Figure 1:

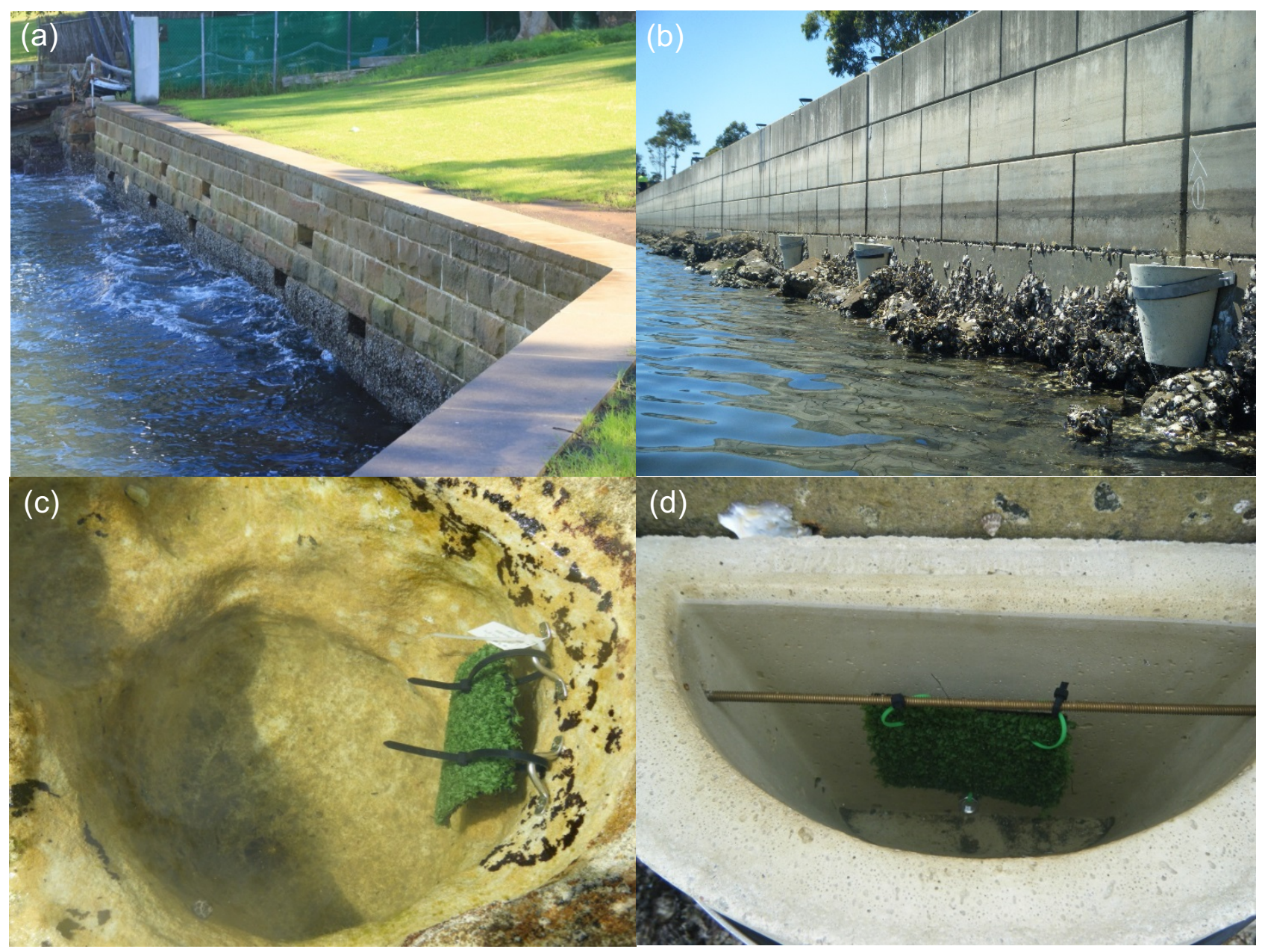

793 
Pre-proof: Please see Morris, R.L., Martinez, A.S., Firth, L.B. and Coleman, R.A., 2018. Can transplanting enhance mobile marine invertebrates in ecologically engineered rock pools?. Marine Environmental Research 141: 119-127. https://www.sciencedirect.com/science/article/pii/S0141113618303404

Figure 2:

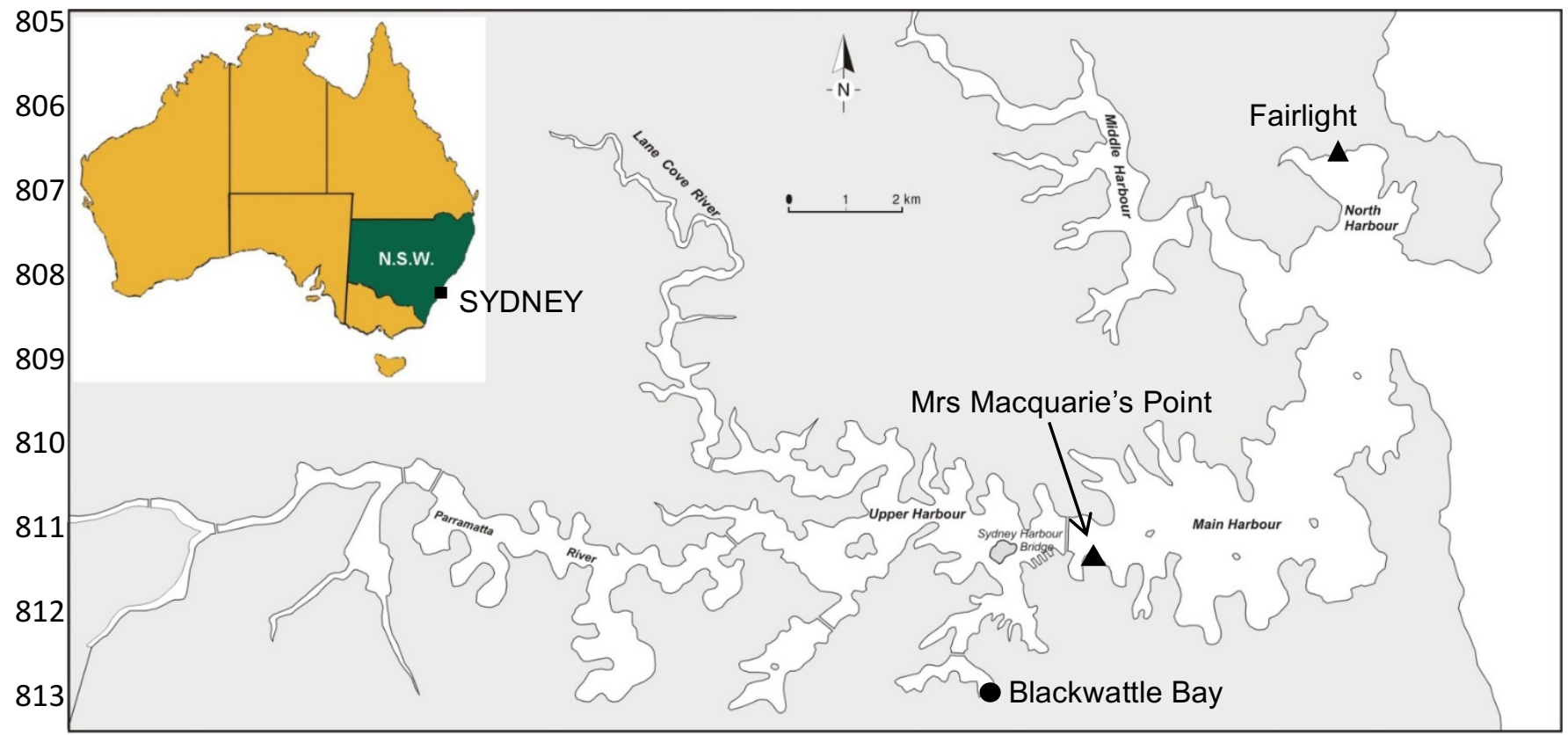


Pre-proof: Please see Morris, R.L., Martinez, A.S., Firth, L.B. and Coleman, R.A., 2018. Can transplanting enhance mobile marine invertebrates in ecologically engineered rock pools?. Marine Environmental Research 141: 119-127. https://www.sciencedirect.com/science/article/pii/S0141113618303404

820

821

822

823

824

825

826

827

828 
Pre-proof: Please see Morris, R.L., Martinez, A.S., Firth, L.B. and Coleman, R.A., 2018. Can transplanting enhance mobile marine invertebrates in ecologically engineered rock pools?. Marine Environmental Research 141: 119-127. https://www.sciencedirect.com/science/article/pii/S0141113618303404

829 Figure 3:

(a)
A. porcata

B. nanum

P. exigua
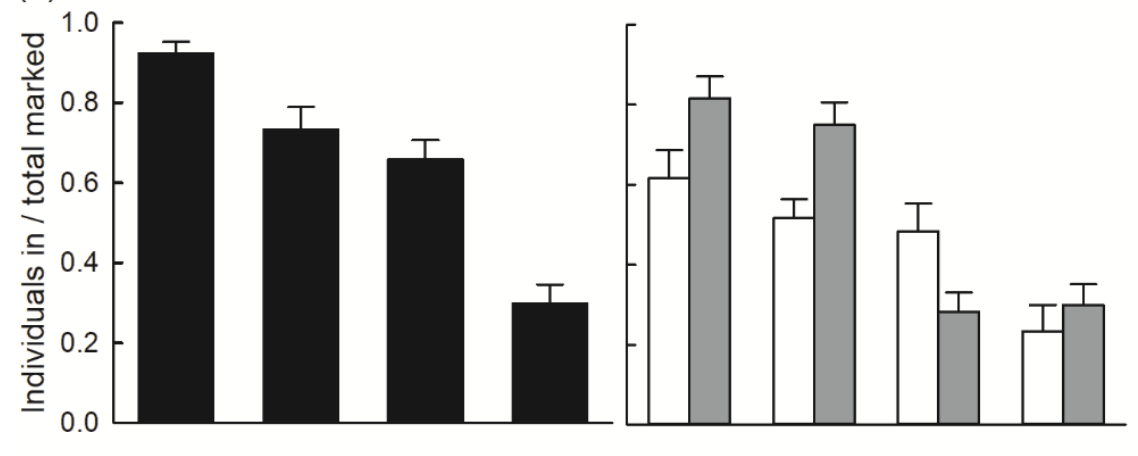

(b)

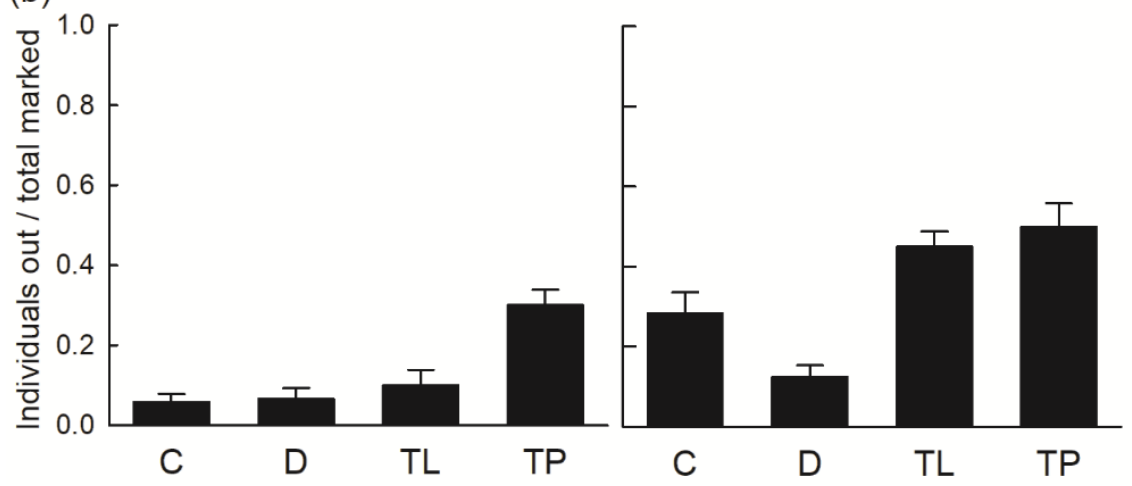

830

831 